\title{
Level of Anxiety \& Depression among Mentally Ill Patients at the National Institute of Mental Health and Hospital
}

\author{
Jesmin Akter $^{1 *}$, Hamidur Rahman ${ }^{2}$
}

${ }^{1}$ Clinical Instructor Enam Nursing College Savar, Dhaka, Bangladesh

${ }^{2}$ Senior Staff Nurse Dhaka Medical College Hospital, Bangladesh

DOI: $10.36347 /$ sjmcr.2021.v09i01.024

| Received: 12.01.2021 | Accepted: 24.01.2021 | Published: 30.01.2021

*Corresponding author: Jesmin Akter

\section{Abstract}

Original Research Article

Background: In Bangladesh, NIMHH in Dhaka is the government institute where mentally ill people are treated. The hospital provides medical treatment and also nursing care for mentally ill people. Mental illness is concerning as a burning issue in the mental health sector. Objectives: To find out possible anxiety \&depression related causes for the increase level among mentally ill patient in National Institute of Mental Health and Hospital, determine the socioeconomic condition of the mentally ill patient. Methodology: The study design was used the cross-sectional study method study. The researcher selected 40 samples in contact with this study. DASS-21 is a self-report instruments consisting of three seven-item subscales to assess depression, anxiety, and stress. (SPSS), by using descriptive statistic method, version 20, and Microsoft Excel 13. Results: If the study result concludes, the participants' mean age was $( \pm 24.50 \%)$, and $45 \%$ of respondents were 11 to 20 years of age. $42.5 \%$ were male, and $57.5 \%$ were female respondents in the study. Maximum respondents were students, 37.5\% [1]. Majority of the respondents' $30.0 \%$ were completed high school level, followed by $25.0 \%$ completed their secondary school level and others. Maximum participants live in a single family, where $30 \%$ in a large family. This study also aimed to identify the level of depression, stress, and anxiety by a scale (DASS-21). My total participants were 40 where in case of "Depression level" " $75 \%$ participants reported that it was hard for him to have the' initiatives to do the thing' where in case of "Anxiety level" $82.5 \%$ participants reported that there 'mouth feels dry' and also for "Stress level" 75\% participants reported that they found it 'difficult to calm himself.' Conclusion: Anxiety and depression is a critical mental disorder which creates harmful effects on health. This research demonstrates that the level of anxiety and depression. This study also found that the socio-demographic characteristics like age, sex, marital status, education, occupation, religion, family size, family income, etc., are related to depression \& anxiety [2].

Keyword: Depression, Anxiety, level, Illness, Mental illness.

Copyright $\odot 2021$ The Author(s): This is an open-access article distributed under the terms of the Creative Commons Attribution 4.0 International License (CC BY-NC 4.0) which permits unrestricted use, distribution, and reproduction in any medium for non-commercial use provided the original author and source are credited.

\section{INTRODUCTION}

In Bangladesh, NIMHH in Dhaka is the government institute where mentally ill people are treated. The hospital provides medical treatment and also nursing care for mentally ill people. Mental illness is a burning issue in the mental health sector [3].

In 2012, a study was carried out at the National Institute of Mental Health and Hospital in Bangladesh, which found that 25,508 people get treatment facilities as new outdoor patients; 2,030 as emergency patients, and 1,953 as indoor patients. $14,959(58.7 \%)$ males, $8,939(35.0 \%)$ females and $1,610(6.3 \%)$ children can take treatment facilities from outdoor. In indoor settings $1,159(59.3 \%)$ males, $667(34.2 \%)$ females and 127
$(6.5 \%)$ children can get treatment facilities. A total of $78.3 \%$ admitted patients take treatment from NIMH\&H in which bipolar mood disorder (40.2\%) and schizophrenia (38.1).

In the general hospital, the physician observes that a large number of patients come with emotional disorders further that disorders contribute to emotional distress and illness. Neglect is the most common barrier for detecting emotional disorders and lack of physician confidence [4].

Depression also causes severe pain in any part of the body. The symptoms of depression are low selfesteem, hopelessness, devaluation of life, selfdeprecation, and inertia. Discuss methods that can 
Jesmin Akter \& Hamidur Rahman., Sch J Med Case Rep, Jan, 2021; 9(1): 87-95

prevent patient anxiety about their condition. Physiological arousal is the most common symptom of anxiety. The anxiety and depression reliable scale is translated validated in much language and used in many ethnic groups. It is used to assess mentally tolerant symptoms in clinical and non-ethical adult samples.

Depressed mood people have insomnia; excessive sleeping, fatigue, aches, pains, digestive problems, and energy loss present with individual depression. Depression in adulthood sometimes causes neglect, mental abuse, physical abuse, and sexual abuse in childhood.

The interrelation between depression and anxiety, some researchers have been inflaming the investigation. How many psychological statuses of these differ from another person? Therefore, few researchers made factor analysis in order to take the discriminate validity of scale items [5].

Chronic illness is at high risk for the patient's psychological problem. On another side, chronic disease impact the bad affect for anxiety and depression disorder. Chronic mental illness significantly affected negatively their individual emotion, beliefs, value, perception, thought and behavior [6].

\section{Research question}

What is the level of anxiety and depression among mentally ill patients at National Institute of Mental Health and Hospital?

\section{Aim of the study \\ To identify anxiety and depression among the mentally ill patients at the National Institute of Mental Health and Hospital}

\section{Study Objective}

\section{General objectives}

To identify the possible anxiety and depression level among mentally ill patients at the National Institute of Mental Health and Hospital

\section{Specific objectives}

- To explore the socio-economic status of the participants.

- To assess the physical status of the participants.

- To find out the level of anxiety and depression of the participants.

- To identify the stress level of the participants.

The serious effect on the neurological outcome of stroke patients [7]

\section{Methodology \\ Study design}

The study design was used in the crosssectional study design. The quantitative method was appropriate for this study. Under the quantitative approach, the researcher used cross-sectional methods that is one type of observational research, involves data collection from a population, or a representative subset, at one specific point in time. According to Levin, a Cross-sectional study analyzes the present situation and is carried out at one specific time or over a short period. The cross-sectional studies provide a snapshot of the outcome and characteristics associated with it at one particular point in time. Usually, there is no hypothesis, but the aim is to describe a population or a subgroup within the people for an outcome and set risk factors [8].

The purpose of the study was to find out the increase level of anxiety and depression among mentally ill patient at National Institute of Mental Health. Data had been collected within three months. In this present study, the researcher had also investigated the association between the respondents' level and demographic factors and patient with anxiety and depression. Cross-sectional studies are useful to identify associations that can then be more rigorously studied using a cohort study or randomized controlled study [9].

\section{Study setting}

The study was conducted in the inpatients and outpatients unit of the NIMHH at Dhaka in Bangladesh. The institute was established in 2001 with the aim of providing quality care to people with mental illness in Bangladesh. As a result, patients are the representative all over the country.

\section{Study population}

All the medical ill peoples in Bangladesh were the study population in the study.

\section{Sampling procedure}

The researcher was chosen the non-probability sampling procedure, which was a convenience sampling strategy. Convenience sampling is a process in which a sample is drawn from the conveniently available subjects. The procedure included all the patients with anxiety and depression who met the inclusion and exclusion criteria.

\section{Sample size}

in this study.

The researcher selected 40samples in contact

\section{Inclusion criteria}

- The participants were patients with anxiety and depression.

- All inpatients and outpatients.

- Patients were selected patients who took the National Institute of Mental Health and Hospital treatment in Dhaka, Bangladesh.

\section{Exclusion criteria}

- Unstable patients. 
- A patient who was unable to provide information properly.

- A patient who was not interested in giving data.

\section{Field test}

The researcher accomplished the field test after starting the data collection with the questionnaire feasible the researcher translate the main questionnaires in Bengali with different people. The researcher had given the information to the participants about the aim and objective of the study. Then the researcher performed field testing with anxiety and depression patients. It was conduct to check the wording was both appropriate and understandable [10].

\section{Data collection technique}

In order to collect data, the researcher conducts face to face interviews about the level of anxiety and depression through a structured questionnaire.

\section{Data collection tools and Instruments}

Socio-demographic profile sheet: This questionnaire was developed by the researcher and includes items related to personal characteristics, such as age, sex, marital status, education, occupation, duration of illness, family size, family income, and relationship with the patient. Paper, pen, pencil, eraser, sharpener, writing board, information sheet, and consent form.

\section{DASS-21 description}

DASS-21 is a self-report instruments consisting of three seven-item subscales to assess depression, anxiety, and stress over the last week. Seven item anxiety, seven-item depression, and sevenitem stress.

\section{Data collection procedure}

Firstly, in order to collect data, the researcher obtained permission from the Nursing department and director of NIMHH. The researcher fixed a date and time with the participant, according to her availability. The aim of the study and the study procedure was explained to participants before collecting data. The participant was given information sheets, and consent forms, and these were described by the researcher. Participants had an opportunity to ask the question, and they signed the consent form after being if they were satisfied. The researcher completed the signed questionnaire on the consent form with regards to demographic data. After that, the researcher collected the demographic information from the participant. Face to face interview the interviewer had a chance to understand the nonverbal cues given by the interview who may indicate confusion or lack of understanding [11]. The interviewer helped the interviewee to understand the questions by changing some words with the same meaning. The entire interview was conducted in Bengali, whereas questionnaire was translated into Bengali following Linguistic validation guidelines of the MAPI Researcher Institute for translation. The researcher has explained the question in a local language that will be helpful to the participant.

\section{Data Analysis}

Data were analyzed through data entry, and analysis was performed using the Statistical Package for social science (SPSS), by using descriptive statistic method, version 20, and Microsoft Excel 13. The presentation of data was organized in SPSS and Microsoft Office Word [12]. All data were input within the variable of SPSS. The DASS and Demographic questionnaire were analyzed. Data were analyzed by descriptive statistics bar, which was the table, pie chart, and Chi-square test.

\section{Chi-Square Test}

The Chi-Square test is the most popular discrete data hypothesis testing method. It is a nonparametric test of statistical significance for bivariate tabular analysis with a contingency table. Chisquare helps us analyze data that come in the form of counts. This test can be applied to nominal or categorical data, which cannot be analyzed using the ranking techniques [13].

\section{The situation for chi-square Test}

- Test of association between two events in binomial samples.

- Test of association between two events in multinomial samples.

\section{Requirements}

1. The data must be in the form of frequencies counted in each of a set of categories.

2. Total numbers observed must exceed 20.

3 . The expected frequency in anyone fraction must not normally be less than 5 .

4. All the observations must be independent of each other. In other words, one observation must not influence another observation.

\section{Formula}

$$
\begin{aligned}
& \quad(\mathrm{x}) \mathrm{x}=\sum_{\mathrm{i}=1}^{\mathrm{k}} \frac{(\mathrm{O}-\mathrm{E})^{2}}{\mathrm{E}} \\
& =\frac{(01-\mathrm{E} 1)^{2}}{\mathrm{E} 1}+\frac{(\mathrm{O} 2-\mathrm{E} 2)^{2}}{\mathrm{E} 2}+\frac{(\mathrm{O} 3-\mathrm{E} 3)^{2}}{\mathrm{E} 3}+\frac{(04-\mathrm{E} 4)^{2}}{\mathrm{E} 4} \\
& =2.02+1.50+2.47+1.83 \\
& =7.82
\end{aligned}
$$


Table-1: Correlation between Depression level and Gender

\begin{tabular}{|c|c|c|c|c|c|c|}
\hline \multicolumn{4}{|l|}{ Depression level\& Gender } & \multicolumn{3}{|c|}{ Pearson Chi-Square Test } \\
\hline Questionnaire & Sex & Yes & No & df & $\begin{array}{l}P \\
\text { value }\end{array}$ & Asymp. Sig. \\
\hline \multirow{2}{*}{$\begin{array}{l}\text { I did not experience any positive } \\
\text { feelings }\end{array}$} & Male & 5 & 12 & \multirow[t]{2}{*}{1} & \multirow[t]{2}{*}{7.82} & \multirow[t]{2}{*}{.005} \\
\hline & Female & 17 & 6 & & & \\
\hline \multirow{2}{*}{$\begin{array}{l}\text { It was hard for me to have the } \\
\text { initiatives to do thing }\end{array}$} & Male & 14 & 3 & \multirow[t]{2}{*}{1} & \multirow[t]{2}{*}{0.85} & \multirow[t]{2}{*}{.356} \\
\hline & Female & 16 & 7 & & & \\
\hline \multirow[t]{2}{*}{ I felt I had no desire for anything } & Male & 8 & 9 & \multirow[t]{2}{*}{1} & \multirow[t]{2}{*}{18.51} & \multirow[t]{2}{*}{.554} \\
\hline & Female & 13 & 10 & & & \\
\hline \multirow{2}{*}{$\begin{array}{l}\text { I felt depressed and had no } \\
\text { motivation }\end{array}$} & Male & 6 & 11 & \multirow[t]{2}{*}{1} & \multirow[t]{2}{*}{0.27} & \multirow[t]{2}{*}{.428} \\
\hline & Female & 17 & 12 & & & \\
\hline \multirow{2}{*}{$\begin{array}{l}\text { I did not feel enthusiastic about } \\
\text { anything }\end{array}$} & Male & 10 & 7 & \multirow[t]{2}{*}{1} & \multirow[t]{2}{*}{1.75} & \multirow[t]{2}{*}{.185} \\
\hline & Female & 18 & 5 & & & \\
\hline \multirow[t]{2}{*}{ I felt like I was worthless as a person } & Male & 13 & 4 & \multirow[t]{2}{*}{1} & \multirow[t]{2}{*}{1.08} & \multirow[t]{2}{*}{.298} \\
\hline & Female & 14 & 9 & & & \\
\hline \multirow[t]{2}{*}{ I felt there was no meaning in life } & Male & 13 & 4 & \multirow[t]{2}{*}{1} & \multirow[t]{2}{*}{0.6} & \multirow[t]{2}{*}{.443} \\
\hline & Female & 15 & 8 & & & \\
\hline
\end{tabular}

Table-2: Correlation between Anxiety level and Gender

\begin{tabular}{|c|c|c|c|c|c|c|}
\hline \multicolumn{4}{|l|}{ Anxiety Level \& Gender } & \multicolumn{3}{|c|}{ Pearson Chi-Square Test } \\
\hline Questionnaire & Sex & Yes & No & df & $\begin{array}{l}\text { P- } \\
\text { value }\end{array}$ & $\begin{array}{l}\text { Asymp. } \\
\text { Sig. }\end{array}$ \\
\hline \multirow{2}{*}{ My mouth feels dry } & Male & 15 & 2 & \multirow[t]{2}{*}{1} & \multirow[t]{2}{*}{26.46} & \multirow[t]{2}{*}{.412} \\
\hline & Female & 18 & 5 & & & \\
\hline \multirow[t]{2}{*}{ I had difficulty breathing at times } & Male & 14 & 3 & \multirow[t]{2}{*}{1} & \multirow[t]{2}{*}{0.4} & \multirow[t]{2}{*}{.749} \\
\hline & Female & 18 & 5 & & & \\
\hline \multirow[t]{2}{*}{ I felt shaky (for example: my hands). } & Male & 16 & 1 & \multirow[t]{2}{*}{1} & \multirow[t]{2}{*}{4.74} & \multirow[t]{2}{*}{030} \\
\hline & Female & 15 & 8 & & & \\
\hline \multirow{2}{*}{$\begin{array}{l}\text { I got worried about situations in which I could have } \\
\text { panicked and looked ridiculous. }\end{array}$} & Male & 7 & 10 & \multirow[t]{2}{*}{1} & \multirow[t]{2}{*}{0.18} & \multirow[t]{2}{*}{.680} \\
\hline & Female & 8 & 15 & & & \\
\hline \multirow[t]{2}{*}{ I felt like I was going to panic } & Male & 7 & 10 & \multirow[t]{2}{*}{1} & \multirow[t]{2}{*}{3.22} & \multirow[t]{2}{*}{.073} \\
\hline & Female & 16 & 7 & & & \\
\hline \multirow{2}{*}{$\begin{array}{l}\text { I knew my heartbeat had changed even though I hadn't } \\
\text { done anything physically rigorous }\end{array}$} & Male & 11 & 6 & \multirow[t]{2}{*}{1} & \multirow[t]{2}{*}{0.27} & \multirow[t]{2}{*}{601} \\
\hline & Female & 13 & 10 & & & \\
\hline \multirow[t]{2}{*}{ I felt afraid for no reason } & Male & 14 & 3 & \multirow[t]{2}{*}{1} & \multirow[t]{2}{*}{0.4} & \multirow[t]{2}{*}{.749} \\
\hline & Female & 18 & 5 & & & \\
\hline
\end{tabular}

\section{Ethical consideration}

At first, when the researcher submitted the proposal, and it was approved, then take permission from the ethical board. The researcher took approval from the ethical committee of nursing department to do the study. Then permission was taken from the Incharge of NIMHH for data collection from the patients by ensuring participants' safety. The participant, who was interested in participating in the study, was informed verbally about the topic and purpose of the study [15]. They were informed about the number of interviews and length of the interview. It was informed that there would be no risk or direct benefit to participating in the study. Each participant had the right to refuse to answer any question or withdraw them from the study. The study participants were voluntary. The investigator did ensure the confidentiality of all information obtained. The investigator did not hamper the activity of the patients during data collection. It was informed that participant's information would be published given by participant will be published according to their permission and at this time their identities will be protected by using coding. Here the world Health Organization and Bangladesh Medical Research Councils rules were followed.

\section{Dissemination OF RESUlT}

This academic research must be done for completing the Degree of B.Sc in Nursing. The research will be published in the BHPI library, the academic institute of Centre for the Rehabilitation of the Paralyzed. A printed copy will go to nursing department.

\section{ResulTS}

The results were shown the association between the level of anxiety, depression and sociodemographic characteristics of the mentally ill patients with anxiety and depression. 
Socio-demographic characteristics of the participants $(\mathrm{N}=40)$

\section{Age range}

The mean age of the participants in the study was 24.50. Among the total participants $(n=40), 45 \%$ $(\mathrm{n}=18)$ respondents were in 11 to 20 years age and $32.5 \%(\mathrm{n}=13)$ were in 21 to 30 years (Table: 1$)$.

Table-1: Age range of the participants

\begin{tabular}{|l|l|}
\hline Age range & Number(percent) \\
\hline $1-10$ & $(2.5 \%) 1$ \\
\hline $11-20$ & $(45 \%) 18$ \\
\hline $21-30$ & $(32.5 \%) 13$ \\
\hline $31-40$ & $(17.5 \%) 7$ \\
\hline $41-50$ & $(5 \%) 2$ \\
\hline Total & $(100 \%) 40$ \\
\hline
\end{tabular}

\section{Gender}

Total participants of the study were 40 . Among them, $42.5 \%(n=17)$ were male and $57.5 \%(n=23)$ were female (Figure.1).

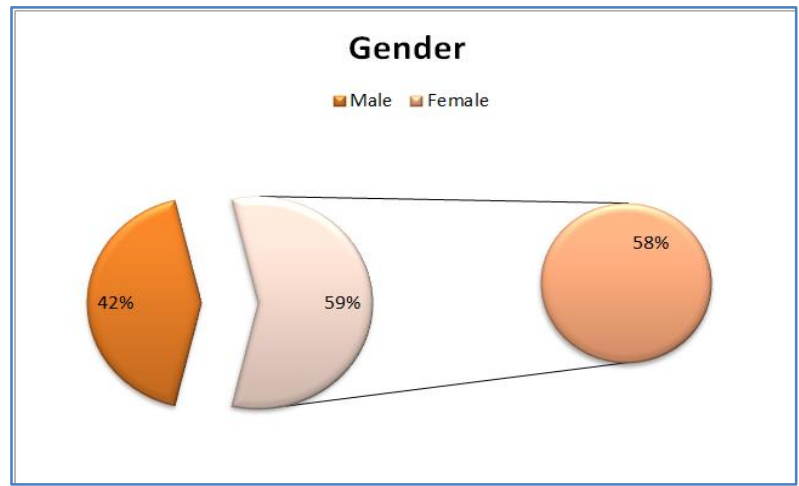

Fig-1: Percentage of gender of the participants

\section{Marital status}

Most of the respondents were married $52.5 \%$ $(n=21)$ followed by unmarried $47.5 \%(n=19)$ in this study (figure: 2 ).

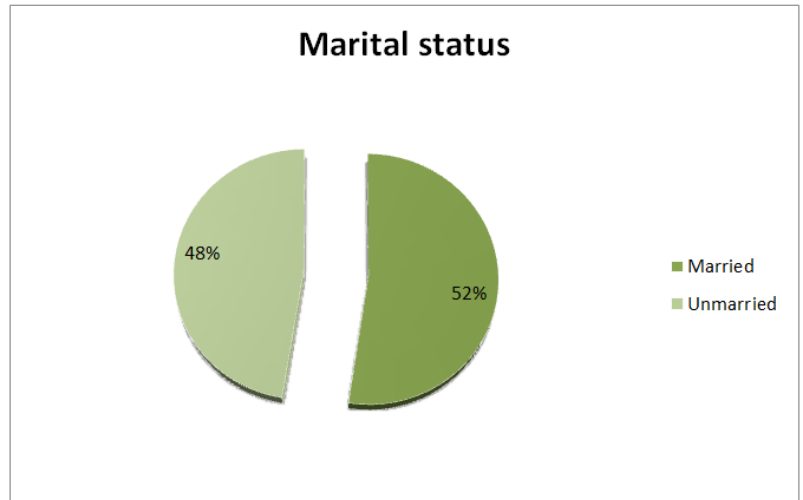

Fig-2: Percentage of marital status of the participants

\section{Occupation}

Most of the Respondents were students $37.5 \%$ $(n=15)$, housewife $(n=10) 25.0 \%$, business $(n=4) 10 \%$, Govt. employee $7.5 \%(n=3)$ Non-govt. employee $7.5 \%$ $(n=3)$ others $12.5 \%(n=5)$ in this study (Table: 2$)$.

Table-2: Occupational status of the participants

\begin{tabular}{|l|l|l|}
\hline & Frequency & Percent \\
\hline Students & 15 & $37.5 \%$ \\
\hline Govt. employee & 3 & $7.5 \%$ \\
\hline Non-govt. employee & 3 & $7.5 \%$ \\
\hline Business & 4 & $10.0 \%$ \\
\hline Housewife & 10 & $25.0 \%$ \\
\hline Others & 5 & $12.5 \%$ \\
\hline Total & 40 & $100.0 \%$ \\
\hline
\end{tabular}

\section{Educational qualification}

Majority of the respondent's 30.0\% $(n=12)$ were completed high school level followed by $25.0 \%$ $(n=10)$ were completed their secondary school level, higher secondary school level $17.5 \% \quad(n=7)$ Primary school level $15.0 \% \quad(n=6)$ illiterate $10.0 \% \quad(n=4)$ graduate $2.55 \% \quad(n=1)$ in this study (Table: 3$)$.

Table-3: Educational status of the participants

\begin{tabular}{|l|l|l|}
\hline & Frequency & Percent \\
\hline Illiterate & 4 & $10.0 \%$ \\
\hline Primary school level & 6 & $15.0 \%$ \\
\hline High school level & 12 & $30.0 \%$ \\
\hline Secondary school certificate & 10 & $25.0 \%$ \\
\hline Higher secondary school certificate & 7 & $17.5 \%$ \\
\hline Graduate and above & 1 & $2.5 \%$ \\
\hline \multicolumn{1}{|c|}{ Total } & 40 & $100.0 \%$ \\
\hline
\end{tabular}




\section{Religion}

Majority of the respondents were Muslim 90\% $(n=36)$ Hindu $10 \%(n=4)$ in this study (Figure: 3$)$.

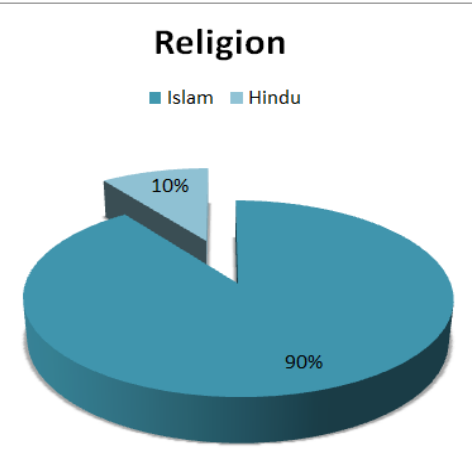

Fig-3: Percentage of religion status of the participants

\section{Family size}

Most of the respondents live in the singlefamily $70 \%(\mathrm{n}=28)$ followed by large family $30 \%$ $(\mathrm{n}=12)$ in this study (Figure: 4$)$.

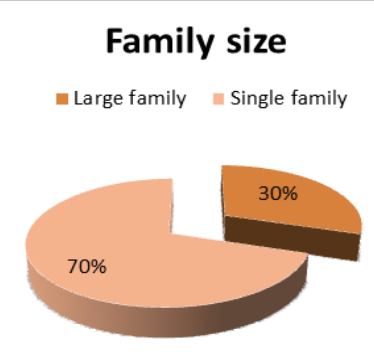

Fig-4: Percentage of family size of the participants

\section{Family income}

The maximum amounts are 30000taka and minimum amounts are 2000taka. Most of the respondent's incomes were $37.5 \%(n=15) 6000-10000$ tk $\& 22.5 \%(n=9) 11000-15000$ taka (Table: 4).

Table-4: Family income of the participants

\begin{tabular}{|l|c|}
\hline Income range & Number/Percent \\
\hline $1000-5000$ & $(15 \%) 6$ \\
\hline $6000-10000$ & $(37.5 \%) 15$ \\
\hline $11000-15000$ & $(22.5 \%) 9$ \\
\hline $16000-20000$ & $(10 \%) 4$ \\
\hline $21000-25000$ & $(7.5 \%) 3$ \\
\hline $26000-30000$ & $(7.5 \%) 3$ \\
\hline Total & $(100 \%) 40$ \\
\hline
\end{tabular}

\section{Depression Anxiety and Stress Scale -21}

\section{Depression level}

In this study, $75 \%$ of participants reported that it was hard for him to have the' initiatives to do the thing'. Secondly, most common symptoms were 'did not feel enthusiastic' about anything and $70 \%$ of participants reported it where similar $(70 \%)$ participants reported that they felt there was 'no meaning of life'. $67.5 \%$ participants reported that they felt worthless as a person, which were the third most common symptoms among the participants. Among the participants, 55\% reported they 'did not experience any positive feelings' whilst $52.5 \%$ of participants reported them 'felt they had no desire for anything,' and $42.5 \%$ of participants reported they 'felt depressed and had no motivation (Table: 5)'.

Table-5: Depression level of the participants

\begin{tabular}{|l|l|l|l|}
\hline No & Questionnaire & Percentage \\
\cline { 3 - 4 } & & Yes & No \\
\hline 1 & I did not experience any positive feelings & $55 \%$ & $45 \%$ \\
\hline 2 & It was hard for me to have the initiatives to do the thing & $75 \%$ & $25 \%$ \\
\hline 3 & I felt I had no desire for anything & $52.5 \%$ & $47.5 \%$ \\
\hline 4 & I felt depressed and had no motivation & $42.5 \%$ & $57.5 \%$ \\
\hline 5 & I did not feel enthusiastic about anything & $70 \%$ & $30 \%$ \\
\hline 6 & I felt like I was worthless as a person & $67.5 \%$ & $32.5 \%$ \\
\hline 7 & I felt there was no meaning of life & $70 \%$ & $30 \%$ \\
\hline
\end{tabular}

\section{Anxiety Level}

In this study, $82.5 \%$ of participants reported that there 'mouth feels dry'. Secondly, most common symptoms were 'had difficulty breathing' at times and $80 \%$ of participants reported it where similar $(80 \%)$ participants reported that they 'felt afraid for no reason.' $77.5 \%$ of participants reported that they felt shaky (for example: my hands) and it was the third most common symptoms among the participants. Among the participants, 60\% reported they 'knew there heartbeat had changed even though there hadn't done anything physically rigorous' whilst $57.5 \%$ participants reported them 'felt like they were going to panic' and $37.5 \%$ participants reported they 'I got worried about situations in which they could have 'panicked and looked ridiculous 'and 62.5\% didn't reported it (Table: $6)$. 
Table-6: Anxiety level of the participants

\begin{tabular}{|l|l|l|l|}
\hline No & Questionnaire & \multicolumn{2}{l|}{ Percentage } \\
\cline { 3 - 3 } & & Yes & No \\
\hline 01 & My mouth feels dry & $82.5 \%$ & $17.5 \%$ \\
\hline 02 & I had difficulty breathing at times & $80.0 \%$ & $20.0 \%$ \\
\hline 03 & I felt shaky(for example: my hands) & $77.5 \%$ & $22.5 \%$ \\
\hline 04 & $\begin{array}{l}\text { I got worried about situations in which I could have panicked } \\
\text { and looked ridiculous }\end{array}$ & $37.5 \%$ & $62.5 \%$ \\
\hline 05 & I felt like I was going to panic & $57.5 \%$ & $42.5 \%$ \\
\hline 06 & $\begin{array}{l}\text { I knew my heartbeat had changed even though I hadn't done } \\
\text { anything physically rigorous }\end{array}$ & $60 \%$ & $40 \%$ \\
\hline 07 & I felt afraid for no reason & $80 \%$ & $20 \%$ \\
\hline
\end{tabular}

\section{Stress Level}

In this study, $75 \%$ of participants reported that they found it 'difficult to calm him.' Secondly, most common symptoms were 'they intended to exaggerate when they reacted to situation and $77.5 \%$ participants reported it.72.5\% participants reported that they felt they were always nervous and it was the third most common symptoms among the participants. Among the participants, $65 \%$ reported they 'they felt restlessness' whilst $62.5 \%$ participants reported them 'they were intolerant of the things that kept there from continuing to do what they had been doing'. 65\% they didn't find it difficult to relax, and $62.5 \%$ of participants reported they didn't feel like we're being a little too emotional' (Table: 7).

Table-7: Stress level of the participants

\begin{tabular}{|l|l|l|l|}
\hline No & Questionnaire & \multicolumn{2}{|l|}{ Percentage } \\
\cline { 3 - 4 } & & Yes & No \\
\hline 01 & I found it difficult to clam my self & $85 \%$ & $15 \%$ \\
\hline 02 & I intended to exaggerate when I reacted to situation & $77.5 \%$ & $22.5 \%$ \\
\hline 03 & I felt I was always nervous & $72.5 \%$ & $27.5 \%$ \\
\hline 04 & I felt restlessness & $65 \%$ & $35 \%$ \\
\hline 05 & I found it difficult to relax & $35 \%$ & $65 \%$ \\
\hline 06 & I felt like I was a little too emotional & $37.5 \%$ & $62.5 \%$ \\
\hline 07 & I was intolerant of the things that kept me from continuing to do what I had been doing & $62.5 \%$ & $37.5 \%$ \\
\hline
\end{tabular}

\section{Correlation between Depression level \& Gender}

Since calculate value of (7.82) is greater than the table (3.84) with $1 \mathrm{df}$ at $5 \%$ level of significance, $\mathrm{p}<.005$. Hence, we conclude that a real association exists between gender and depression level.

Since calculating value of (18.51) is greater than the table (3.84) with $1 \mathrm{df}$ at $5 \%$ level of significance, $\mathrm{p}<.554$. Hence, we conclude that not a real association exists between gender and depression level.

\section{Correlation between Anxiety level \& Gender}

Since calculate value of (26.46) is greater than the table (3.84) with $1 \mathrm{df}$ at $5 \%$ level of significance, $\mathrm{p}<.412$ Hence, we conclude that not a real association exists between gender and anxiety level.

Since calculate value of (4.74) is greater than the table (3.84) with $1 \mathrm{df}$ at $5 \%$ level of significance, $\mathrm{p}<.030$. Hence, we conclude that a real association exists between gender and anxiety level.

\section{DISCUSSION}

In the discussion section, analysis of the level of anxiety, depression and socio-demographic characteristics of the mentally ill patients with anxiety and depression will be reviewed. Socio-demographic characteristics are age, sex, marital status, education, occupation, religion, family size, family income, etc.

The mean age of the participants in the study was $( \pm 24.50 \%)$. Among the total participants, $45 \%$ were in 11 to 20 years of age and $32.5 \%$ were in 21 to 30 years. In a study, sample consisted only of adolescents where $179(57.7 \%)$ males, overall mean of the sample were $14.16 \%( \pm 2.12)$ years [13].

Total participants in the study were 40 . Among them, $42.5 \%$ were male and $57.5 \%$ were female. In this study, Eighteen percent of the women were anxious and depressed.

Most of the respondents were married at $52.5 \%$ followed by unmarried at $47.5 \%$ in this study. In Nigerian study PWS $16.6 \%$ were married, $44.3 \%$ were single, $32.1 \%$ separated, $3.0 \%$ divorced and $1.4 \%$ were widowed.

Most of the respondents were students $37.5 \%$ whilst, housewife $25.0 \%$, business $10 \%$, Govt. employee $7.5 \%$ Non-govt. employee $7.5 \%$ others $12.5 \%$ in this study. Psychological distress was associated with 
Jesmin Akter \& Hamidur Rahman., Sch J Med Case Rep, Jan, 2021; 9(1): 87-95

husband unemployment ( $\mathrm{p}=0.032)$, lower household wealth $(p=0.027)$, having 10 or more years of formal education $(\mathrm{p}=0.002)$, a first $(\mathrm{p}=0.002) \&$ an unwanted pregnancy $(\mathrm{p}<0.001)[9]$.

Majority of the respondents' $30.0 \%$ were completed high school level followed by $25.0 \%$ completed their secondary school level, higher secondary school level $17.5 \%$ Primary school level $15.0 \%$ illiterate $10.0 \%$ graduate $2.55 \%$ in this study . The studies suggest a high prevalence of depression and anxiety among medical students with levels of overall psychological distress consistently higher than in the general population.

Most of the respondents live in the singlefamily $70 \%$ followed by a large family $30 \%$. The study reported that the strong relations between higher levels of parenting stress were significantly related to more child problem behavior.

The maximum incomes are 30000tk and minimum incomes are 2000tk. Most of the respondent's incomes were $37.5 \%$ 6000-100000tk \& $22.5 \%$ were 11000-15000tk. In this study, stress was associated with depression and anxiety levels, also related to Childs behavioral symptoms, maternal anxiety; maternal depressive symptoms, and lack of governmental financial support.

\section{Depression Anxiety and Stress Scale -21}

\section{Depression level}

In this study, $75 \%$ of participants reported that it was hard for him to have the' initiatives to do thing'. Secondly, most common symptoms were 'did not feel enthusiastic' about anything and $70 \%$ of participants reported it where similar (70\%) participants reported that they felt there was 'no meaning of life'. $67.5 \%$ of participants reported that they felt worthless as a person, which was the third most common symptoms among the participants. Among the participants, 55\% reported they 'did not experience any positive feelings' whilst 52.5\% participants reported them 'felt they had no desire for anything' and $42.5 \%$ reported they 'felt depressed and had no motivation'. In the study HADSdepression with and without the "slowed down" item detected similar rates of depression: $30.6 \%$ and $31.6 \%$ respectively [13].

\section{Anxiety Level}

In this study, $82.5 \%$ participants reported that there 'mouth feels dry'. Secondly, most common symptoms were 'had difficulty breathing' at times and $80 \%$ participants reported it where similar (80\%) participants reported that they 'felt afraid without any reason'. $77.5 \%$ participants reported that they felt shaky (for example: my hands) and it was the third most common symptoms among the participants. Among the participants, $60 \%$ reported they 'knew there heartbeat had changed even though there hadn't done anything physically rigorous' whilst $57.5 \%$ participants reported as they 'felt like they were going to panic' and $37.5 \%$ participants reported as "they got worried about situations in which they could have 'panicked and looked ridiculous 'and $62.5 \%$ didn't reported it. A bifactor structure with depression, anxiety, stress and a general factor provided the best fit index for the DASS21.

\section{Stress level}

In this study, $75 \%$ participants reported that, they found it 'difficult to calm him or her'. Secondly, most common symptoms were 'they intended to exaggerate when they reacted to situation and $77.5 \%$ participants reported it.72.5\% participants reported that, they felt they were always nervous and it was the third most common symptoms among the participants. Among the participants, 65\% reported they 'they felt restlessness' whilst $62.5 \%$ participants reported them 'they were intolerant of the things that kept there from continuing to do what they had been doing'. Also, $65 \%$ reported they didn't find any difficult to relax, and $62.5 \%$ reported they didn't feel like we were being a little too emotional'. In other study, convergent validity was adequate for the depression and anxiety subscale but more ambiguous for the stress subscale [13].

\section{CONCLUSION}

Anxiety and depression is a critical mental disorder which creates harmful effects on the health. This research demonstrates that the level of anxiety and depression. In this study, it was also found that the socio-demographic characteristics like age, sex, marital status, education, occupation, religion, family size, family income, etc. are much related to depression and anxiety.

If the study result concludes, the mean age of the participants was $( \pm 24.50 \%)$ and $45 \%$ were in 11 to 20 years age. $42.5 \%$ were male and $57.5 \%$ were female respondents in the study. Maximum respondents were students $37.5 \%$. Majority of the respondents' $30.0 \%$ were completed high school level followed by $25.0 \%$ completed their secondary school level and others. Maximum participants lives in single family where $30 \%$ in large family.

Also the aim of this study was to identify the level of depression, stress and anxiety by a scale (DASS-21).My total participants were 40 where in case of "Depression level" "75\% participants reported that it was hard for him to have the' initiatives to do thing' where in case of "Anxiety level" $82.5 \%$ participants reported that there 'mouth feels dry' and also for "Stress level" 75\% participants reported that they found it 'difficult to calm himself'. The scale reflected the level depression, anxiety and stress. If I want relive their depression, anxiety and stress I have to organize a team to provide information about anxiety and 
Jesmin Akter \& Hamidur Rahman., Sch J Med Case Rep, Jan, 2021; 9(1): 87-95

depression among the participants. The national survey can be conduct to know the prevalence of anxiety and depression, health care and other facilities. If we work together, we can improve the participant's knowledge about anxiety, depression and prevent psychological problem and other health problem related to anxiety, depression and stress.

\section{RECOMMENDATION}

Future similar research will be conducted in the area with large number of sample size. And also need for more research on the level of anxiety and depression among mentally ill patients at NIMHH. To prevent the depression, anxiety among the patients. Education and proper counseling to help them to obtain the beneficial outcomes and avoid the negative outcomes that is possible. Nurses need to pay more attention to patients' personal and anxiety depression level and to carefully identify their needs. The information regarding the findings should be conveyed to the patients so they can advocate for themselves. Family support can contribute to a better anxiety and depression of the patients.

\section{REFERENCES}

1. Abbas TS, Ebrahimnia M, Shamspour N, Assari S. Antidepressants for treating depression in adults with end- stage kidney disease treated with dialysis. The Cochrane Library; 2009.

2. Badmil K, Duman ZÇ. Caregivers of Schizophrenia patients.Psikiyatride Guncel Yaklasimlar-Current Approaches in Psychiatry. 2013; 5:461-478.

3. Barker P. Psychiatric and mental health nursing: the craft of caring. CRC Press.2008.

4. Bhugra D. Schizophrenia: Care Intervention in the treatment and management in Adults in primary and secondary care. 2010.

5. Canat S. Depression, Anxiety and Stress Scale (DASS): The Study of Validity and Reliability. Universal Journal of Educational Research. 2007; 4(12), 2701-2705.

6. Das S, Hazra A, Ray BK, Ghosal M, Banerjee TK, Roy T, Chaudhuri A, Raut DK, Das SK. Burden among stroke caregivers: results of a community- based study from Kolkata, India. Stroke. 2010 Dec 1;41(12):2965-8.

7. Fortinsky RH, Tennen H, Frank N, Affleck G. Anxiety and Depression among the Caregivers of patients with Neurological illness; 2007.

8. Ilse IB, Feys H, De Wit L, Putman K and De Weerdt W. Stroke caregivers' strain: prevalence and determinants in the first six months after stroke. Disability and Rehabilitation. 2008; 30(7), 523-530.

9. Karmaliani R, Asad N, Bann CM, Moss N, Mcclure EM, Pasha O, Wright LL, Goldenberg RL. Prevalence of anxiety, depression and associated factors among pregnant women of Hyderabad, Pakistan. International Journal of Social Psychiatry. 2009 Sep;55(5):414-24.

10. Lewis SC, Dennis MS, O'Rourke SJ, Sharpe M. Negative attitudes among short-term stroke survivors predict worse long-term survival. Stroke. $2001 \mathrm{Jul} ; 32(7): 1640-5$.

11. Martinez-Martin P, Benito-Leon J, Alonso F, Catalan MJ, Pondal M, Zamarbide I, Tobias A, De Pedro J. Quality of life of caregivers in Parkinson's disease. Quality of life research. 2005 Mar 1;14(2):463-72.

12. Norton S, Sacker A, Done J. Further research needed: A comment on Coyne and van Sonderen's call to abandon the Hospital Anxiety and Depression Scale.

13. Patel VP, Feinstein A. Comparison of two versions of the Hospital Anxiety and Depression Scale in assessing depression in a neurologic setting. Cognitive And Behavioral Neurology. 2017 Dec 1;30(4):145-9.

14. Testa A, Giannuzzi R, Daini S, Bernardini L, Petrongolo L, Gentiloni Silveri N. Psychiatric emergencies (part III): psychiatric symptoms resulting from organic diseases. Eur Rev Med Pharmacol Sci. 2013 Feb 1;17(Suppl 1):86-99.

15. Yesufu-Udechuku A, Harrison B, Mayo-Wilson E, Young N, Woodhams P, Shiers D, Kuipers E, Kendall T. Interventions to improve the experience of caring for people with severe mental illness: systematic review and meta-analysis. The British Journal of Psychiatry. 2015 Apr;206(4):268-74. 